\title{
Marcadores tumorais no câncer de pulmão: um caminho para a terapia biológica*
}

\author{
Fernando Azevedo Pacheco ${ }^{1}$, Marcos Eduardo Machado Paschoal ${ }^{2}$, Maria da Glória da Costa Carvalho 3
}

Os avanços recentes na genética e na biologia molecular permitiram a identificação de genes e proteínas produzidos ou superexpressados pelos tumores. Tais produtos, os chamados marcadores tumorais, antes utilizados apenas como ferramentas de diagnóstico e prognóstico, vêm atualmente tomando papel importante no desenvolvimento de novas modalidades de tratamento, direcionadas a quebrar o ciclo biológico da progressão tumoral. Neste artigo, revisa-se o papel de alguns marcadores tumorais tradicionalmente conhecidos (CEA, p53, NSE, K-ras), e descrevem-se a prevalência e a função da superexpressão do receptor do fator de crescimento epidérmico (EGFR) e do seu produto protéico (p185 neu). Novos agentes têm sido desenvolvidos baseando-se no bloqueio da sinalização iniciada pelo EGFR. Destes, destaca-se o ZD1839 (Iressa), uma droga via oral que inibe de modo reversível e seletivo a atividade tirosina-quinase do EGFR, e que vem demonstrando bons resultados tanto isoladamente quanto em combinação com outros agentes quimioterápicos. Tais avanços devem contribuir de modo significativo no tratamento do câncer, principalmente no carcinoma de pulmão do tipo não-pequenas células. (J Pneumol 2002;28(3):143-149)

\section{Tumor markers in lung cancer: a pathway to biological therapy}

Recent advances in genetics and molecular biology lead to the identification of genes and protein products overexpressed by tumors. Such products, called tumor markers, were previously used only as diagnostic and prognostic tools, but are currently being the target of extensive research, with growing evidence that some of them may have an important role in the development of new treatment modalities, targeting the tumor cell biological cycle. In this article, the authors review the role of some of the traditionally known tumor markers (CEA, p53, NSE, K-ras), and describe the prevalence and the role of the epidermal growth factor receptor (EGFR) overexpression and its protein product, $\mathrm{p} 185^{\text {neu. }}$. New drugs have been developed, aiming at the blockade of the signaling process initiated by the EGFR. Among these, the authors highlight ZD1839 (Iressa), a new orally administered drug that reversibly and selectively inhibits the EGFR tyrosine-kinase activity. This drug has demonstrated good results in the treatment of non-small-cell lung cancer, as an isolated drug or in combination with other chemotherapy agents. Targeting the EGFR could represent a significant contribution to cancer therapy, mainly the non-small-cell lung cancer.

Descritores - Carcinoma pulmonar de células não pequenas. Terapia biológica. Anticorpos monoclonais. Neoplasias pulmonares. Marcadores biológicos de tumor. Receptor do fator de crescimento epidérmico. Antígeno carcinoembrionário.

Key words - Lung neoplasms. Tumor markers. Receptor epidermal growth factor. Carcinoembryonic antigen. Antibodies. Monoclonal. Biological therapy. Carcinoma, non-small-cell lung.
Siglas e abreviaturas utilizadas neste trabalho APUD - Amine Precursor Uptake and Decarboxilation CEA - Antígeno carcinoembrionário

CPNPC - Carcinoma de pulmão tipo não-pequenas células

CPPC - Carcinoma de pulmão tipo pequenas células

EGFR - Receptor do fator de crescimento epidérmico

GDP - Guanosina difosfato

GTP - Guanosina trifosfato

NSE - Enolase neurônio-específica

3. Laboratório de Controle da Expressão Gênica.

Endereço para correspondência - Av. Brig. Trompowski, S/N, sala 3F92 - 21941-590 - Rio de Janeiro, RJ. Tel. (21) 2290-8099. Fax (21) 2290-8099. E-mail: mempasch@ biof.ufrj.br

Recebido para publicação em 8/2/02. Aprovado, após revisão, em 22/4/02.
* Trabalho realizado no Serviço de Pneumologia do Hospital Universitário Clementino Fraga Filho, Universidade Federal do Rio de J aneiro, Rio de J aneiro, RJ .

1. Mestrando em Pneumologia; Coordenador do Serviço de Pneumologia.

2. Chefe do Ambulatório de Oncopneumologia. 


\section{INTRODUÇÃO}

Apesar dos avanços no diagnóstico e tratamento do câncer de pulmão ocorridos nas últimas décadas, este continua sendo a principal causa de morte por neoplasia nos EUA, tanto no sexo masculino quanto no feminino(1). No Brasil, é a principal causa de morte oncológica entre os homens e a segunda principal entre as mulheres, ficando atrás apenas do câncer de mama(2).

A quimioterapia, antes um tratamento de exceção no carcinoma broncogênico, é hoje em dia utilizado na maior parte dos pacientes com doença não ressecável (principalmente estádios IIIB e IV), os quais podem constituir até 80 a $85 \%$ dos casos novos ${ }^{(3)}$. A sua utilização como tratamento neo-adjuvante no estádio IIIA ampliou ainda mais o uso dos quimioterápicos. Apesar do desenvolvimento de novos agentes quimioterápicos, com melhores perfis de tolerância e toxicidade, pouco se alterou em termos de mortalidade em relação aos esquemas clássicos baseados em platina.

A busca por marcadores séricos ou teciduais que permitam o diagnóstico precoce do câncer de pulmão é uma aspiração antiga. Os marcadores tumorais deveriam ser, em tese, produtos tumorais que fossem detectados antes mesmo do desenvolvimento macroscópico do tumor, permitindo, então, a intervenção médica antes do processo de invasão tumoral, angiogênese e disseminação metastática. Com isso, alterar-se-ia de forma muito significativa o prognóstico da doença, com maiores índices de tratamento de pacientes em estágios 0 ou 1 e maiores possibilidades de cura. Infelizmente, grande parte disso não ocorre. Ao longo das últimas décadas, vários marcadores tumorais foram descritos e estudados, porém nenhum deles conseguiu alcançar tais objetivos propostos, ou seja, deteç̧ão precoce e precisa do tumor. A seguir, revisamos os marcado res tumo rais mais conhecidos, e suas reais aplicações na prática diária.

\section{Antígeno carcinoembrionário (CEA)}

Descrito em 1965 por Gold e Freedman, o antígeno carcinoembrionário (CEA) constitui-se de uma glicoproteína originalmente relacionada com o adenocarcinoma de cólon e reto(4). Produzido pelas células do epitélio glandular secretor de mucina do feto, o CEA pode ter níveis elevados nos carcinomas com diferenciação glandular, sendo um dos primeiros marcadores tumorais correlacionados com câncer de pulmão. Pode estar presente em baixos níveis em tecidos não neoplásicos e não fetais. Aparentemente, o CEA permanece como um dos poucos marcadores tumorais séricos de interesse permanente nos carcinomas de pulmão não-pequenas células, mais particularmente e previsivelmente os adenocarcinomas ${ }^{(5)}$.
Gasser et al. consideram o CEA como o marcador tumoral mais valioso na avaliação dos carcinomas não-pequenas células(6).

A maioria dos adenocarcinomas de pulmão apresenta esse antígeno elevado. Analisando-se os carcinomas de pulmão globalmente, o antígeno carcinoembrionário se encontra elevado em até $66 \%$ dos casos, sendo também encontrado no carcinoma de células escamosas e no de pequenas células ${ }^{(7)}$. Entretanto, a maioria dos tabagistas também apresenta o antígeno carcinoembrionário elevado no sangue, sem que haja malignidade reconhecida, pulmonar ou não. Tal fato parece decorrer da agressão direta da fumaça aspirada sobre o epitélio respiratório, levando à liberação do antígeno para o sangue ${ }^{(8)}$. Ainda com relação a esse aspecto, alguns pesquisadores sugerem que o CEA poderia ser um indicador genérico de suscetibilidade a doenças pulmonares nos tabagistas com seu nível sérico elevado(9). Presumivelmente, o antígeno carcinoembrionário possui baixa sensibilidade e especificidade como método de screening e seus níveis séricos se encontrarão tão mais elevados quanto mais avançada for a malignidade. Seu valor como monitor terapêutico para o câncer de pulmão ainda não foi firmemente estabelecido, embora esteja relatada sua reascensão nos pacientes tratados e com recidiva da doença. Até o presente momento, por via de regra, aconselha-se que o CEA não seja tomado como base de decisões clínicas.

É um gene supressor que tem função na proteção da estrutura do DNA. Ele regula o ciclo celular, fazendo a célula estacionar o seu ciclo biológico até que as proteínas de reparo do DNA possam agir. Se as alterações genéticas forem de tal magnitude que o reparo seja impossível, o gene p53 inicia o processo de apoptose (morte celular programada) ${ }^{(10)}$. Mutações no gene p53 são as alterações genéticas mais freqüentes no câncer de pulmão e em alguns existe supressão molecular ou funcional do p53(11).

Mais de $50 \%$ dos tumores malignos apresentam mutação pontual em um dos alelos do p53 e perda do outro. Estas mutações podem ser devidas a fatores ambientais (como dieta, poluição, fumo) ou genéticos. 0 gene supressor de tumor p53 situa-se no braço curto do cromossoma 17 , na posição $17 \mathrm{p} 13.1^{(12)}$. O produto do gene p53 é uma fosfoproteína nuclear de $53 \mathrm{kDa}$ com capacidade de se ligar especificamente ao DNA e ativar a transcrição. Os mecanismos moleculares pelos quais a p53 funciona normalmente e como estes mecanismos são alterados durante a tumorigênese ainda não são completamente compreendidos. Nos últimos anos, várias evidências experimentais têm demonstrado que a proteína p53 selvagem pode regular negativamente a proliferação celular. Um dos genes induzidos pela p53 é o p21/WAF1, um inibidor de CDKs $s^{(13)}$. A p53 normal pode induzir p21, que inibe cdk4, resultando em defosforilação do $\mathrm{Rb}$ e, 
conseqüentemente, inibição do ciclo celular. Em resposta a danos no DNA a p53 leva a uma parada do ciclo celular na fase de transição de $\mathrm{G} 1$ para $\mathrm{S}$, permitindo à célula reparar a integridade de seu genoma. Quando os danos no DNA são irreversíveis e não podem ser reparados, a p53 induz a célula a entrar em apoptose ${ }^{(14)}$.

Mutações no gene da p53 eliminam a sua capacidade de mediar a parada no ciclo celular. Mutação no gene p53 é uma das ocorrências mais freqüentes em câncer de pulmão, sendo detectada em mais de $70 \%$ em câncer escamoso ${ }^{(15,16)}$ e em mais de $90 \%$ em SCLC ${ }^{(17)}$. Alguns trabalhos relacionam pior prognóstico com mutações na p53 ${ }^{(18)}$, porém outros não encontram associação(19).

Anticorpos contra p53 têm sido encontrados em pacientes com câncer de pulmão e a presença destes parece estar relacionada com a presença de mutações no tumor ${ }^{(20)}$. A presença de anticorpos contra p53 pode preceder o desenvolvimento clínico do câncer ${ }^{(21)}$. Pequenas quantidades de DNA livre no plasma ou soro podem ser detectadas em pessoas sadias; contudo, este nível está aumentado em várias neoplasias malignas ${ }^{(22,23)}$. 0 DNA circulante apresenta as mesmas mutações que o tumor. Recentemente, em pacientes brasileiros com câncer de pulmão(24) foi relatada a presença de $29 \%$ e $20 \%$ de DNA circulante contendo genes K-ras e TP53, respectivamente.

\section{ENOLASE NEURÔNIO-ESPECÍFICA (NSE)}

Descrita inicialmente, em 1965, por Moore e McGregor, como enzima catalisadora da via glicolítica anaeróbia, a enolase se encontra distribuída em todos os tecidos dos mamíferos ${ }^{(25)}$. A isoenzima aa (a-enolase ou enolase não neuronal) é a forma mais comumente encontrada de enolase, sendo localizada na maioria dos tecidos. A subunidade $ß$ ( $ß$-enolase) acha-se predominantemente no tecido muscular estriado e no coração. No sistema nervoso central podemos detectar três tipos da isoenzima enolase - aa, ag e gg. A subunidade g (g-enolase) possui configuração idêntica à da proteína cérebro-específica 14-3-2 isolada do cérebro bovino por Moore e a partir daí as isoenzimas ag e gg foram caracterizadas como enolase neurônio-específica (NSE)(26). Em 1978, Schmechel et al. detectaram enolase neurônio-específica na pineal, hipófise, tiróide, medula adrenal e pâncreas, citando-a como marcador molecular para as células neuroendócrinas centrais e periféricas. Nesse mesmo trabalho os autores antevêem o futuro e especulam que a enolase neurônioespecífica possa vir a ser útil no diagnóstico e tratamento dos tumores do sistema APUD, hoje denominados tumores neuroendócrinos ${ }^{(27)}$. Mais recentemente, utilizando técnicas imunoenzimáticas, altamente sensíveis, níveis significativos da isoenzima ag foram verificados em tecidos não neuroendócrinos, como musculatura lisa, tecido fi- bromuscular, células epiteliais brônquicas e pneumócitos tipo II.

A utilização da enolase neurônio-específica como marcador tumoral do pulmão começa a partir dos trabalhos de Cole et al. em 1980. Estes a descrevem como marcador histoquímico das células pulmonares que tenham diferenciação neuroendócrina na tentativa de correlacionar o pulmão como membro do sistema APUD (28). Em 1981 constata-se, por imunoistoquímica, a presença de níveis elevados de enolase neurônio-específica em tumores neuroendócrinos, como glucagonoma, insulinoma, carcinóide de intestino, feocromocitoma e carcinoma medular da tiróide ${ }^{(29)}$. Em seguida, em 1982, verifica-se sua presença no neuroblastoma e ocorre a correlação entre a enolase neurônio-específica e carcinoma de pulmão de pequenas células ${ }^{(30)}$. Naquele mesmo ano, Carney et al. publicam um trabalho em que consideram a enolase neurônio-específica como marcador de doença extensa e como forma de avaliação da resposta terapêutica no carcinoma de pequenas células(31). Em 1984 foi sugerido que a NSE seja um útil marcador tumoral, assim como método auxiliar de estadiamento (estando significativamente mais elevada na doença extensa), monitor terapêutico e preditor de recidiva de doença nos pacientes com carcinoma de pequenas células tratados ${ }^{(32)}$. A determinação sérica da enolase neurônio-específica parece ser um instrumento valioso para o diagnóstico do carcinoma de pequenas células, combinando aceitável sensibilidade com alto grau de especificidade ${ }^{(33)}$. Além disso, a enolase neurônio-específica pode ser elemento útil na estimativa de extensão da doença, não havendo correlação significativa entre nível sérico e número ou sítios específicos de metástases na doença avançada e entre nível sérico e tissular, mostrando que altos índices tissulares não correspondem a altos níveis séricos da enolase neurônio-específica.

Estudos realizados no Hospital Universitário da Universidade Federal do Rio de J aneiro demonstraram que a NSE, aferida por método imunoenzimático ELISA e estabelecido o ponto de corte de $37 \mathrm{ng} / \mathrm{ml}$, possui sensibilidade de $65 \%$, especificidade de $95 \%$, valor preditivo positivo de $86,7 \%$, valor preditivo negativo de $84,4 \%$, razão de verossimilhança positiva de 13 , razão de verossimilhança negativa de 0,37 e acurácia de $85 \%$ para o carcinoma de pulmão de pequenas células. Observou-se, ainda, sua presença consistentemente mais elevada na doença extensa do que na localizada ${ }^{(34,35)}$.

Em resumo, a dosagem sérica da NSE tem provado ser um valioso instrumento no auxílio diagnóstico do carcinoma de pulmão de pequenas células, com sensibilidade global variando de $60 \%{ }^{(36)}$ a $85 \%{ }^{(33)}$ (média de $77,5 \%$ ) e especificidade variando de $85 \%^{(37)}$ a $95 \%{ }^{(33)}$ (média de $90 \%$ ). Vale lembrar que a sensibilidade é fortemente correlacionada com estágio de doença, podendo na doença 
limitada variar de $32,5 \%{ }^{(36)}$ a $68 \%{ }^{(38)}$ (média $50,3 \%$ ) e de $78,6 \%{ }^{(39)}$ a $100 \%{ }^{(40)}$ (média $89,2 \%$ ) na doença extensa. Fica também evidente, através de sua sensibilidade específica para a doença extensa e limitada, a correlação significativa entre níveis séricos e estadiamento de doença. Tal correlação sugere que a NSE possa ter, também, valor prognóstico, ainda que este fato requeira maior fundamentação por ensaios clínicos e análises estatísticas(41). Outro aspecto concernente à NSE seria sua aplicação como forma de monitor terapêutico, nos pacientes em curso quimioterápico, em que seus valores séricos tendem a subir ou baixar, de acordo com a resposta à terapia empregada e até antever recidiva de doença ${ }^{(42)}$.

\section{K-RAS}

Os proto-oncogenes ras são expressos em vários tipos de células normais e incluem três membros da família: $\mathrm{H}$-, $\mathrm{K}$ - e N-ras. Estes genes codificam proteínas de $21-\mathrm{Kda}$, também chamada de p21, que se encontram ancorados na superfície interna da membrana citoplasmática por lipídeos, adicionados à proteína ras por modificação póstraducional. As proteínas ras são homólogas às proteínas-G e estão ligadas à transdução de sinal do citoplasma para o núcleo via segundo mensageiro através da cascata de proteínas-quinases ativadas por mitógenos (MAP). As proteínas $\mathrm{G}$ existem em dois estados: ligadas a GTP (ativado) e ligadas a GDP (inativas). Somente a forma ligada a GTP é efetiva em mediar a resposta à proliferação celular, existindo uma conversão dinâmica entre as duas formas(43).

Genes mutados da família ras são os oncogenes mais comumente encontrados nas neoplasias malignas humanas ${ }^{(44,45)}$. No câncer de pulmão, mutações pontuais no códon 12 do oncogene K-ras são detectadas em 24-50\% dos adenocarcinomas, sendo raramente observadas nos outros tipos de carcinoma de pulmão(46). Existem discordâncias na literatura em relação à ativação do K-ras durante o desenvolvimento do câncer de pulmão. Li et al.(47) sugerem que a ativação de K-ras seja um evento que ocorra em estágios iniciais que precedem as evidências clínicas do crescimento do tumor. Por outro lado, Sugio et al. ${ }^{(48)}$ argumentam que ativação de K-ras seja um evento tardio baseado em observações de que as mutações são raramente encontradas em epitélio neoplásico adjacente ao carcinoma invasivo de pulmão. Mutações em outros membros da família ras, N- e H-ras, ocorrem com menor freqüência em CPNCP e linhagens celulares.

O significado clínico de mutações em ras em câncer de pulmão é objeto de estudo. Rodenhuis e Slebos(49) demonstraram que tumores contendo mutação em K-ras eram mais agressivos, os pacientes apresentavam tempo livre de doença significativo menor e menor sobrevida quando comparados com os sem mutação em K-ras. No trabalho de Slebos et al. ${ }^{(50)}$, foi verificado que mutações pontuais em K-ras são importante fator de prognóstico para determinar o tempo livre de doença e sobrevida, após variáveis como estadiamento da doença, tamanho do tumor e grau de diferenciação terem sido levadas em consideração.

\section{EGFR/HER2-NEU}

Com o desenvolvimento da biologia molecular e da descoberta de genes e produtos protéicos que regulam 0 crescimento e a progressão tumoral, o foco das pesquisas tem-se voltado para o desenvolvimento de agentes que possam interferir direta ou indiretamente no ciclo biológico da célula neoplásica, e não somente detectá-lo mais precocemente. Isso representa enorme contribuição no tratamento do câncer de pulmão, pois estaríamos objetivando alvos moleculares ao invés de somente células já formadas. Neste campo, a descoberta mais importante talvez tenha sido a dos fatores de crescimento epidérmicos.

0 receptor do fator de crescimento epidérmico (EGFR) regula um caminho de sinalização autócrino que contribui para grande número de processos importantes para 0 desenvolvimento neoplásico, incluindo proliferação celular, apoptose (morte celular programada), angiogênese e disseminação metastática. Esse papel crítico do EGFR levou a intensa busca por inibidores seletivos do caminho de sinalização iniciado pela ativação do EGFR. O EGFR é parte de uma subfamília de quatro receptores intimamente relacionados: EGFR (ou ErbB-1), HER-2/neu (ErbB-2), HER3 (ErbB-3) e HER-4 (ErbB-4)(51,52). A pós a junção de um ligante, o domínio intracelular tirosina-quinase do receptor é ativado, levando à autofosforilação do domínio intracelular, que inicia uma cascata de eventos intracelulares.

0 gene c-erbB-2 encontra-se superexpressado em várias neoplasias humanas, incluindo cerca de um terço dos carcinomas de pulmão tipo não-pequenas células(53). No adenocarcinoma de pulmão, o produto protéico da c-erbB2 é observado em 28 a 38\% dos casos, e associado a pior prognóstico ${ }^{(54)}$. 0 produto protéico do HER2-neu é a proteína p185, uma glicoproteína transmembrana, que possui atividade tirosina-quinase e participa na transdução de sinal intracelular. Sua expressão em tecidos humanos normais é baixa e ocorre infreqüentemente ${ }^{(55)}$. A amplificação do proto-oncogene HER-2/neu também ocorre em $15-40 \%$ dos carcinomas primários de mama e 30\% dos carcinomas de ovário ${ }^{(56,57)}$. Sua expressão no sangue periférico se correlaciona com a carga tumoral, encontrando-se em níveis mais aumentados ( $>22 \mathrm{U} / \mathrm{mL}$ ) nos tumores estádio IIIB e IV ${ }^{(58)}$. Pode, porém, ser detectado antes mesmo do diagnóstico clínico, estando elevado precocemente no processo de carcinogênese ${ }^{(59)}$.

Com base nesses dados, o EGFR passou a ser alvo para o desenvolvimento de drogas que pudessem bloquear a 
sua ativação. Duas abordagens terapêuticas mostraramse promissoras e são atualmente estudadas: 1) anticorpos monoclonais e 2) pequenas moléculas inibidoras da atividade tirosina-quinase do EGFR. Enquanto os anticorpos monoclonais são direcionados para o domínio externo do EGFR, as pequenas moléculas previnem a autofosforilação do domínio intracelular do EGFR.

\section{USO DOS NOVOS MARCADORES TUMORAIS NA TERAPIA ANTINEOPLÁSICA}

\section{1) Anticorpos monoclonais contra o EGFR}

O IMC-C225 (cetuximab) é um anticorpo monoclonal quimérico (humano-rato) que se liga ao EGFR com grande afinidade e é capaz de bloquear a autofosforilação induzida pelo EGFR, in vitro(60). Estudos usando células de câncer humano implantadas em ratos demonstraram inibição de angiogênese tumor-induzida. Estes efeitos foram potencializados quando os ratos foram tratados com IMCC255 combinados a gemcitabina ou paclitaxel(61). Experiências in vitro também demonstraram aumento da resposta do tumor à radiação ionizante em células humanas previamente tratadas com IMC-C $255^{(62)}$. Entre os potenciais mecanismos para o aumento da radiossensibilidade, vários estudos sugerem o acúmulo das células neoplásicas nas fases celulares mais radiossensíveis (G 1, G2-M) e o bloqueio dos mecanismos de reparo de DNA.

Estudos clínicos (fase I e fase II) em pacientes com comprovada superexpressão de EGFR já foram realizados em pacientes com carcinoma de cabeça e pescoço, pâncreas, rim e cólon, como agente único ou combinado com quimioterapia. Houve maior taxa de estabilização, resposta e sobrevida livre de doença nos pacientes tratados com C255 do que nos tratados apenas com quimioterapia. Não há ainda estudos sobre o uso de IMC-C255 em carcinoma de pulmão tipo não-pequenas células(63).

2) Pequenas moléculas inibidoras da tirosinaquinase do EGFR

Diversas moléculas inibidoras da tirosina-quinase têm sido sintetizadas e avaliadas em estudos pré-clínicos; estão em desenvolvimento clínico atual a ZD1839 (Iressa), OSI-774, CI-1013 e PKI-166. Destas, ganhou mais popularidade no tratamento do câncer de pulmão a ZD1839 (Iressa).

\section{2a) ZD1839 (Iressa)}

É um inibidor reversível da tirosina-quinase do EGFR, ativo por via oral. Exibe mínima atividade contra outras tirosina-quinases. 0 tratamento com ZD 1839 tem sido associado com um aumento dose-relacionado da apoptose in vitro(64), assim como o bloqueio da angiogênese induzida pelo tumor ${ }^{(65)}$. Sua farmacocinética permite a adminis- tração em dose única diária, por via oral. Sua atividade antitumoral foi observada em pacientes com neoplasia colorretal, ovariana, cabeça e pescoço, renal e, principalmente, no carcinoma de pulmão tipo não-pequenas células (CPNPC). Em publicação recente, foi demonstrada uma resposta completa (mais de oito meses), cinco respostas parciais e oito estabilizações de doença em um grupo de 24 pacientes com CPNPC avançado, tratados com ZD1839 associado a carboplatina e paclitaxel(66). Dois estudos multicêntricos fase III com ZD1839 (250 ou 500mg/dia) em combinação com agentes citotóxicos (carboplatina/paclitaxel ou cisplatina/gemcitabina) foram iniciados, objetivando primeira linha de tratamento em pacientes em estádio III não-cirúrgico ou estádio IV.

\section{2b) $0 \mathrm{SI}-774$}

É também um inibidor reversível da tirosina-quinase do EGFR, ativo por via oral. Encontra-se atualmente em fase II de estudos clínicos para câncer de pulmão (CPNPC), ovário e cabeça e pescoço. Recentemente, foi relatada evidência de atividade antitumoral do 0SI-774 em pacientes com CPNPC avançado que falharam à quimioterapia com platina. U ma resposta completa, seis respostas parciais e 17 estabilizações de doença foram relatadas em 57 pacientes $^{(67)}$.

\section{CONCLUSÕES}

Os marcadores tumorais tradicionais mostram correlação com carga tumoral e prognóstico no câncer de pulmão, porém não conseguem influenciar no diagnóstico precoce ou no planejamento terapêutico do câncer de pulmão. Já os novos marcadores têm aplicação tanto diagnóstica quanto terapêutica, tendo como alvo o comportamento biológico do tumor e a interrupção do seu ciclo celular. O tratamento com IMC-C225, ZD1839 e 0SI-774 como agentes únicos resultou em estabilização da doença, assim como maior número de respostas em distintos tumores primários. Estudos pré-clínicos com IMC-C225, ZD1839 e OSI-774 e resultados clínicos preliminares com IMC-C225 sugerem que seu potencial pode ainda ser aumentado quando em combinação com quimioterapia e radioterapia. 0 aumento da atividade antineoplásica da terapia convencional pela interferência com a ativação do EGFR pode ter implicações clínicas significantes, constituindo uma nova abordagem na terapia oncológica.

\section{REFERÊNCIAS}

1. Greenlee RT, Hill-Harmon MB, Murray T, Thun M. Cancer statistics. CA Cancer J Clin 2001;51:15-36.

2. INCA. Ministério da Saúde. Estimativas da incidência e mortalidade por câncer no Brasil. Brasília, 2001 [cited 2001]. Available from: http:/ /www.inca.org.br. 
3. Shields TW. Surgical therapy for carcinoma of the lung. Clin Chest Med 1993;14:121.

4. Gold P, Friedman SO. Demonstration of tumor-specific antigens in human colonic carcinomata by immunological tolerance and absorption techniques. J Exp Med 1965;121:439-62.

5. Hansen $M$, Pedersen AG. Tumour markers in patients with lung cancer. Chest 1986;89:219-24.

6. Gasser RW, Denz H, Huber H. Tumormarker beim bronchuskarzinom. Wien Klin Wochenschr 1989;101:476-9.

7. Schwartz MK. Biochemical and immunologic diagnosis of cancer. Lung cancer. Tumour Biol 1987;8:134-8.

8. Clarke C, Hine HR, Dykes PW, Whitehead TP, Whitfield AGW. Carcinoembryonic antigen and smoking. J R Coll Physicians Lond 1980; 14:227-8.

9. Merril WW, Goodman M, Mathay RA, Naegel GP, Vandevoorde JP, Myl AD, et al. Quantitation of carcinoembryonic antigen in lung lining fluids of normal smokers and nonsmokers. Am Rev Respir Dis 1981; 123:29-31.

10. Fisher DE. Apoptosis in cancer therapy: crossing the threshold. Cell 1994;78:539.

11. Nathan F. The biology of lung cancer. Semin Oncol 1993;20:105.

12. McBride OW, Merry D, Givol D. The gene for human p53 cellular tumor antigen is located on chromosome 17 short arm (17p13). Proc Natl Acad Sci U S A 1986;83:130-4.

13. El-Deiry WS, Tokino T, Velculescu VE, Levy DB, Parsons R, Trent J M, et al. WAF1, a potential mediator of p53 tumor suppression. Cell 1993; 75:817-25.

14. Lane DP. p53, guardian of the genome. Nature 1992;358:15-6.

15. Marchetti A, Buttitta F, Merlo G, Diella F, Pellegrini A, Pepe $S$, et al. P53 alterations in non-small cell lung cancers correlate with metastatic involvement of hilar and mediastinal lymph nodes. Cancer Res 1993; 53:2846-51.

16. Chiba I, Takahashi T, Nau MM, D'Amico D, Curiel DT, Mitsudomi T, et al. Mutations in the p53 gene are frequent in primary, resected nonsmall cell lung cancer. Oncogene 1990;5:1603-10.

17. D'Amico D, Carbone D, Mitsudomi T, Nau M, Fedorko J, Russell E, et al. High frequency of somatically acquired $p 53$ mutations in small cell lung cancer cell lines and tumors. Oncogene 1992;7:339-46.

18. Horio Y, Takahashi T, Kuroishi T, Hibi K, Suyama M, Nimi T, et al. Prognostic significance of p53 mutations and $3 p$ deletions in primary resected non-small cell lung cancer. Cancer Res 1993;53:1-4.

19. Passlick B, Izbicki IR, Haussinger $K$, Thetter $O$, Pantel K. Immunohistochemical detection of p53 protein is not associated with a poor prognosis in non-small-cell lung cancer. J Thorac Cardiovasc Surg 1995; 109:1205-11.

20. Winter SF, Minna JD, J ohnson BE, Takahashi T, Gazdar AF, Carbone DP. Development of antibodies against p53 in lung cancer patients appears to be dependent on the type of p53 mutation. Cancer Res 1992;52:4168-74.

21. Lubin R, Zalcman G, Bouchet L, Tredanel J, Legros Y, Cazals D, et al. Serum p53 antibodies as early markers of lung cancer. Nat Med 1995; 1:701-2.

22. Stroun $M$, Anker $P$, Maurice $P$, Lyautey J, Lederrey $C$, Beljanski $M$. Neoplastic characteristics of the DNA found in the plasma of cancer patients. Oncology 1989;46:318-22.

23. Stroun M, Anker P, Lyautey J, Lederrey C, Maurice P. Isolations and characterization of DNA from the plasma of cancer patients. Eur J Cancer Clin Oncol 1987;23:707-12.

24. Kawamura MT, Paschoal MEM, Loivos LP, Costa FG, Carvalho MGC Detection of K-ras and TP53 DNA in plasma of patients with lung cancer. 17th International Cancer Congress. International Proceeding Division, 1998;607-10.
25. Moore BW, MCGregor T. Chromatographic and electrophoretic fractionation of soluble proteins of brain and liver. J Biol Chem 1965; 240:1647-53.

26. Marangos PJ, Zomzely-Neurath C, Goodwin FKJ. Structural and immunological properties of neuron specific protein (NSP) from rat, cat and human brain: comparison to bovine 14-3-2. J Neurochem 1977; 28:1097-107.

27. Schmechel D, Marangos PJ, Brightman M. Neurone-specific enolase is a molecular marker for peripheral and central neuroendocrine cells. Nature 1978;276:834-6.

28. Cole GA, Polak JM, Wharton J, Marangos PJ, Pearse AGE. Neuron specific enolase as a useful histochemical marker for the neuroendocrine system of the lung. J Pathol 1980;132:351-2.

29. Tapia FJ, Polak J M, Barbosa AJA, Bloom SR, Marangos PJ, Dermody $C$, et al. Neuron-specific enolase is produced by neuroendocrine tumors. Lancet 1981;1:808-11.

30. Marangos PJ, Gazdar AF, Carney DN. Neuron-specific enolase in human small cell carcinoma cultures. Cancer Lett 1982;15:67.

31. Carney DN, Marangos PJ, Ihde DC, Bunn J r. PA, Cohen MH, Minna $J D$, et al. Serum neuron-specific enolase: a marker for disease extent and response to therapy of small cell lung cancer. Lancet 1982;13: 583-85.

32. J ohnson DH, Marangos PJ, Forbes JT, Hainsworth JD, van Welch R, $H$ ande $K R$, et al. Potential utility of serum neuron-specific enolase levels in small cell carcinoma of the lung. Cancer Res 1984;44:540914.

33. Esscher T, Steinholtz L, Bergh J, Nöu E, Nilsson K, Påhlman S. Neurone specific enolase: a useful diagnostic serum marker for small cell lung carcinoma of the lung. Thorax 1985;40:85-90.

34. Paschoal MEM, Bethlem NM. The value of serum neuron-specific enolase in the valuation of small cell lung cancer [Abstract]. Am Rev Respir Dis 1993;147:A525.

35. Paschoal MEM. Correlation between serum neuron-specific enolase and prognostic factors in small-cell lung cancer [Abstract]. Am J Respir Crit Care Med 1995;150:A163.

36. Fischbach $W$, J any $B$, Nelkenstock R. Bedeutung der neurispezifischen enolase (NSE) in der diagnostik von bronchialkarzinomen und neuroendocrinen tumoren. Dtsch Med Wochenschr 1986;111:1721-5.

37. Burghuber OC, Worofka B, Schernthaner G, Vetter N, Neumann M, Dudczak $R$, et al. Serum neuron-specific enolase is a useful tumor marker for small-cell lung cancer. Cancer 1990;65:1386-90.

38. Cooper EH. Neuron-specific enolase: a marker of (small cell) cancers of neuronal and neuroendocrine origin. Biomed Pharmacother 1985;39: 165-6.

39. Akoun GM, Scarna HM, Milleron BJ, Benichou MP, Herman DP. Serum neuron-specific enolase: a marker for disease extent and response to therapy for small cell lung cancer. Chest 1985;87:38-43.

40. Liippo KK, Terho T. Concomitant monitoring of serum neuron-specific enolase and creatine kinase BB in small cell lung cancer. Acta Oncol 1991;30:321-4.

41. Splinter TAW, Cooper EH, Kho GS, Oosterom R, Peake MD. Neuronspecific enolase as a guide to the treatment of small cell lung cancer. Eur J Cancer Clin Oncol 1987;23:171.

42. Bates SE, Longo DL. Use of serum tumor markers in cancer diagnosis and management. Semin Oncol 1987;14:102-38.

43. Carbone DP. The biology of lung cancer. Semin Oncol 1997;24:388401.

44. Rodenhuis S. Ras and human tumors. Semin Cancer Biol 1992;3: 241-7.

45. Bos J. Ras oncogenes in human cancer: a review. Cancer Res 1989; 49:4682-9. 
46. Milld N, Fishman C, Rom W, Dubin N, Jacobson D. Increased prevalence of $\mathrm{K}$-ras oncogene mutations in lung adenocarcinomas. Cancer Res 1995;55:1444-7.

47. Li Z, Zheng J, Weiss L, Shibata D. c-K-ras and p53 mutations occur very early in adenocarcinoma of lung. Am J Pathol 1994;144:303-9.

48. Sugio K, Kishimoto Y, Virmani AK, Hung J Y, Gazdar AF. K-ras mutations are a relatively late event in the pathogenesis of lung carcinomas. Cancer Res 1994;54:5811-5.

49. Rodenhuis S, Slebos RJ. Clinical significance of ras oncogene activation in human lung cancer. Cancer Res 1992;52(Suppl):2665s-9.

50. Slebos RJ , Kibbelaar RE, Dalesio O, Kooistra A, Stam J, Meijer CJ, et al. K-ras oncogene activation as a prognostic marker in adenocarcinoma of the lung. N Engl J Med 1990;323:561-5.

51. Sedlacek HH. Kinase inhibitors in cancer therapy. A look ahead. Drugs 2000;59:435-76.

52. Wells A. Molecules in focus EGFR receptor. Int J Biochem Cell Biol 1999;31:637-43.

53. Weiner DB, Nordberg J, Robinson R, Nowell PC, Gazdar A, Greene $M I$, et al. Expression of the neu gene-encoded protein ( $185^{\text {neu }}$ ) in human non-small-cell carcinomas of the lung. Cancer Res 1990;50: 421-5.

54. Kern JA, Schwartz DA, Nordberg JE, Weiner DB, Greene MI, Torney $\mathrm{L}$, et al. P185neu expression in human lung adenocarcinoma predicts shortened survival. Cancer Res 1990;50:5184-91.

55. Press MF, Cordon-Cardo C, Slamon DJ. Expression of the HER-2/neu proto-oncogene in normal human adult and fetal tissues. Oncogene 1990;5:953-62.

56. Slamon DJ, Clark GM, Wong SG, Levin WJ, Ullrich A, McGuire WL. Human breast cancer: correlation of relapse and survival with amplification of the HER-2/neu protooncogene. Science 1987;235:177-82.

57. Slamon DJ, Godolphin W, J ones LA, Holt JA, Wong SG, Keith DE, et al. Studies of the HER-2/neu proto-oncogene in human breast and ovarian cancer. Science 1989;244:707-12.

58. Osaki T, Mitsudomi T, Oyama T, Nakanishi R, Yasumoto K. Serum level and tissue expression of c-erbB-2 protein in lung adenocarcinoma. Chest 1995;106:157-62.

59. Brandt-Raulf PW, Luo J C, Carney WP, Smith S, DeVivo I, Milling C, et al. Detection on increased amounts of the extracellular domain on the c-erbB-2 oncoprotein in serum during pulmonary carcinogenesis in humans. Int J Cancer 1994;56:383-6.

60. Goldstein NI, Prewett M, Zuklys K, Rockwell P, Mendelson J. Biological efficacy of a chimeric antibody to the epidermal growth factor receptor in a human tumor xenograft model. Clin Cancer Res 1995;1: 1311-8.

61. Bruns CJ, Harbison MT, Davis DW, Portera CA, Tsan R, McConkey DJ, et al. Epidermal growth factor receptor blockade with C225 plus gemcitabine results in regression of human pancreatic carcinoma growing orthotopicaly in nude mice by antiangiogenic mechanisms. Clin Cancer Res 2000;6:1936-48.

62. Milas L, Mason K, Hunter N, Petersen S, Yamakawa M, Ang K, et al. In vivo enhancement of tumor radioresponse by $C 225$ antiepidermal growth factor receptor antibody. Clin Cancer Res 2000;6:701-8.

63. Ciardello F, Tortora G. A novel approach in the treatment of cancer: targeting the epidermal growth factor receptor. Clin Cancer Res 2001; 7:2958-70.

64. Ciardello F, Caputo R, Bianco R, Damianco V, Pomatico G, De Plácido $S$, et al. Antitumor effect and potentiation of cytotoxic drugs activity in human cancer cells by ZD-1839 (Iressa), an epidermal growth factor receptor-sensitive tyrosine-kinase inhibitor. Clin Cancer Res 2000; 6:2053-63.

65. Ciardello F, Caputo R, Bianco R, Damianco V, Fontanini G, Cuccato $S$, et al. Inhibition of growth factor production and angiogenesis in human cancer cells by ZD1839 (Iressa), a selective epidermal growth factor receptor tyrosine-kinase inhibitor. Clin Cancer Res 2001;7:145965.

66. Miler VA, Johnson D, Heelan RT, Pizzo BA, Perez WJ, Bass A, et al. A pilot study demonstrates the safety of ZD1839 (Iressa), and oral epidermal growth factor receptor tyrosine kinase inhibitor (EGFR-TKI), in combination with cisplatin $(C)$ and paclitaxel $(P)$ in previously untreated advanced non-small-cell lung cancer (NSLC). Proc Am Soc Clin Oncol 2001;21:326.

67. Perez-Soler R, Chachoua A, Huberman M, Karp D, Rigas J, Hammond $L$, et al. A fase II trial of epidermal growth factor receptor (EGFR) tyrosine kinase inhibitor OSI-774, following platinium-based chemotherapy, in patients with advanced, EGFR-expressing, non-small cell lung cancer (NSCLC). Proc Am Soc Clin Oncol 2001;21:310. 